was continued in two patients (cases 1 and 2) for this reason.

Poisoning may result if the method of administering Eumydrin (as a specific number of drops) is not understood $^{6}$ and this should be stressed whenever it is prescribed.

\section{References}

' Braham J, Hertzeanu H. Yahini JH, Neufeld HN. Reflex cardiac arrest presenting as epilepsy. Ann Neurol 1981;10: $277-8$.

2 Stephenson JBP. Reflex anoxic scizures and ocular compression. Dev Med Child Neurol 1980;22:380-6.

${ }^{3}$ Innes IR, Nickerson M. Drugs inhibiting the action of acetylcholine on structures innervated by postganglionic para- sympathetic nerves (antimuscarinic or atropinic drugs). In: Goodman LS, Gilman AG, eds. The pharmacological basis of therapeutics. 6th ed. London: Macmillan, 1980;524-48.

${ }^{4}$ Mewaldt SP, Ghoneim MM. The effects and interactions of scopolamine, physostigmine and methamphetamine on human memory. Pharmacol Biochem Behav 1979;10:205-10.

5 Baumer JH, David TJ, Valentine SJ, Roberts JE, Hughes BR. Many parents think their child is dying when having a first febrile convulsion. Dev Med Child Neurol 1981:23:462-4.

${ }^{6}$ Meerstadt PWD. Atropine poisoning in early infancy duc to Eumydrin drops. Br Med $J$ 1982;285:196-7.

Correspondence to Dr R C McWilliam. Fraser of Allander Unit, Royal Hospital for Sick Children, Yorkhill, Glasgow G3 8SJ.

Received 6 January 1984

\title{
Fat loss during feeding of human milk
}

\author{
I NARAYANAN, B SINGH, AND D HARVEY
}

Queen Charlotte's Maternity Hospital, London

SUMMARY A rise in the fat concentration of human milk within the syringe was noted towards the end of continuous infusion but not with intermittent bolus gastric feeding. The rise in the former was reduced most simply and effectively by using an eccentric nozzle syringe and tilting the pump up at an angle of between $25^{\circ}$ and $40^{\circ}$.

Certain methods of feeding of human milk such as continuous infusion with a syringe are associated with a rise in fat concentration towards the end of the feed. ${ }^{1}$ We have also observed that some pumps retain this energy rich terminal milk in the syringe. We compared the fat concentration at the end of two types of enteral feeding and evaluated some methods of avoiding an excessive rise in this during infusion of human milk.

\section{Material and methods}

The fat in milk samples was estimated by the creamatocrit method ${ }^{2}$ at the beginning and at the end of two types of feeding-continuous infusion using a syringe pump and intermittent bolus gastric feeding. It was observed that while some pumps emptied completely at the end of a feed there was retention of about $2 \mathrm{ml}$ milk in the barrel of others. To estimate the fat concentration towards the end of the feed the pumps were stopped when $2 \mathrm{ml}$ milk remained in the syringe. Infusion feeding was studied using central and eccentric nozzle syringes and by alternative techniques detailed in the first column in the Table. Preliminary investigations showed that with the eccentric nozzle syringe fat retention was greater with the pump sloped up at angles less than $17^{\circ}$ and more than $45^{\circ}$. Further investigations were therefore limited to positions within that range. In intermittent bolus gastric feeding the syringe was detached from the feeding tube when $2 \mathrm{ml}$ milk remained in the barrel. All continuous infusions lasted between 3 and 4 hours and intermittent bolus feeding between 5 and 15 minutes. The results were subjected to standard statistical tests.

\section{Results}

The fat concentrations at the beginning and end of the feed and the difference between these values (mean (SD)) for the various methods are shown in the Table. There was no rise with intermittent bolus feeding (method (a)) and even when a sample of milk was aspirated from the feeding tube at the end of a feed fat concentration was not increased.

With the central nozzle syringe the rise in fat concentration was highest in the conventional method with the pump kept horizontal (method (b)1), increasing to a maximum of $40 \%$. When some milk was aspirated from the tube the concentration 
Table Variations in fat concentration during feeding of human milk (estimated by creamatocrit method ${ }^{2}$; values percentage mean $(S D)$ )

\begin{tabular}{|c|c|c|c|c|}
\hline Method & $\begin{array}{l}\text { No of } \\
\text { studies }\end{array}$ & $\begin{array}{l}\text { Initial } \\
\text { concentration }\end{array}$ & $\begin{array}{l}\text { Final } \\
\text { concentration }\end{array}$ & Difference \\
\hline & 50 & $6 \cdot 3(1 \cdot 7)$ & $5 \cdot 9(1 \cdot 7)$ & $-0 \cdot 3(0 \cdot 5)$ \\
\hline \multicolumn{2}{|l|}{ (b) Continuous infusion } & & & \\
\hline 1 Horizontal & 50 & $5 \cdot 4(2 \cdot 4)$ & $26 \cdot 8(5 \cdot 3)$ & $21 \cdot 4(6 \cdot 0)$ \\
\hline 2 Vertical & 10 & $3.7(0 \cdot 8)$ & $16 \cdot 2(3 \cdot 2)$ & $12 \cdot 5(3 \cdot 5)$ \\
\hline 3 Horizontal with hourly mixing by syringe agitation & 10 & $4.8(1.4)$ & $26 \cdot 7(2 \cdot 7)$ & $21.9(2.0)$ \\
\hline 4 Horizontal with half hourly mixing & 10 & $5 \cdot 5(1 \cdot 5)$ & $10 \cdot 2(1 \cdot 2)$ & $4.6(0.7)$ \\
\hline 5 Vertical with hourly mixing & 10 & $4.9(0.9)$ & $9.7(0 \cdot 6)$ & $4.8(0.6)$ \\
\hline \multicolumn{5}{|l|}{ Eccentric nozzle syringe } \\
\hline 6 Horizontal & 10 & $4 \cdot 2(1 \cdot 1)$ & $17 \cdot 0(2 \cdot 6)$ & $12 \cdot 8(2 \cdot 1)$ \\
\hline 7 Horizontal with hourly mixing & 10 & $4 \cdot 5(1 \cdot 0)$ & $11 \cdot 1(2 \cdot 2)$ & $6.6(1.5)$ \\
\hline 8 Oblique $-17^{\circ}$ & 10 & $4.6(0 \cdot 8)$ & $12 \cdot 2(2 \cdot 0)$ & $8.0(1.7)$ \\
\hline 9 Oblique $-25^{\circ}$ & 10 & $4.8(1.0)$ & $7 \cdot 3(1.6)$ & $2 \cdot 5(1 \cdot 3)$ \\
\hline 10 Oblique $-37^{\circ}$ & 10 & $3 \cdot 8(0 \cdot 8)$ & $7 \cdot 1(1 \cdot 5)$ & $3 \cdot 3(1 \cdot 0)$ \\
\hline 11 Oblique $-40^{\circ}$ & 10 & $4 \cdot 1(1 \cdot 0)$ & $7.2(1.5)$ & $3 \cdot 1(1 \cdot 1)$ \\
\hline 12 Oblique $-45^{\circ}$ & 10 & $3 \cdot 2(1 \cdot 1)$ & $11.9(2 \cdot 6)$ & $8.7(1.8)$ \\
\hline
\end{tabular}

was at times as high as $50 \%$. With the exception of method (b)3 (that is hourly agitation of the syringe) terminal fat concentration was significantly lower with other methods such as (b) 2 and 6 (Table) $(\mathrm{P}<0 \cdot 01)$, even lower with the alternative techniques listed, and was least with an eccentric nozzle syringe tilted up at an angle of $25^{\circ}$ to $40^{\circ}$ (methods (b) 9,10 , and 11). Accidentally, the eccentric nozzle syringe was placed with the nozzle tilted up but on the lower side of the barrel on two occasions, and for obvious reasons the rise in the fat at the end of these feeds was extremely high- $-40 \%$ and $45 \%$ respectively.

A prototype wooden wedge (Figure) was constructed by the local engineering department with a

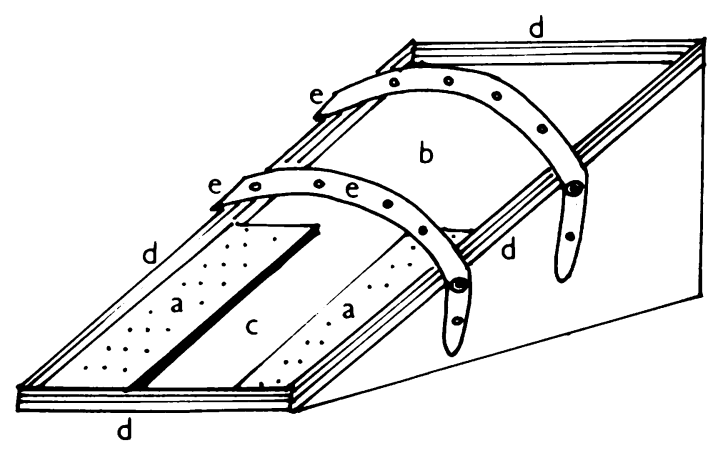

Figure The ramp used in the study for supporting the infusion pump in an oblique position.

This was broad enough to accommodate different types of pumps. Two strips of wood fixed on either side (dotted areas (a)) allowed placement of wider pumps with back projections on part (b). Long narrow pumps could rest in the shallow trough (c). A raised ridge (d) at the periphery prevented the pumps from sliding off. Further stability was achieved with rubber straps (e) fixed to hooks on the side of the ramp. ramp at an angle of $25^{\circ}$ to the horizontal; this narrower angle was selected to make the wedge more stable. The ramp was tested in the unit and no problems such as leaking of milk from the back of the syringe were noted by the nurses. Central nozzle syringes were also tried on this ramp as currently available eccentric nozzle syringes fitted into only some of the infusion pumps. The percentage rise in fat with the latter was mean (SD) $12 \cdot 1(3 \cdot 6)$, which was greater than with the eccentric nozzle syringe in the same position $(\mathrm{P}<0 \cdot 01)$, but less than with the central nozzle syringe in the conventional horizontal position $(\mathrm{P}<0 \cdot 01)$.

\section{Discussion}

Separation of fat in human milk during continuous infusion may contribute to an appreciable fat loss during prolonged periods of feeding, especially if some of the fat rich milk is left in the syringe at the end of each feed. One method of avoiding this would be to homogenise the milk but it is preferable to minimise processing human milk so that its unique properties are retained better.

A simple way to reduce fat loss is to ensure that the syringe is completely emptied at the end of each feed. With the conventional infusion method, however, terminal fat concentration can be excessive-up to $40 \%$ or more. While there is some rise in the milk fat concentration towards the end of normal breast feeding which is physiological, ${ }^{34}$ the rise during conventional infusion seems to be abnormal. In fact, it would be almost equivalent to introducing a small pat of butter every 3 to 4 hours and could not be physiological. Periodic agitation of the syringe to keep the fat concentration more uniform can be carried out but it is time consuming 
and has the potential risk of causing separation of solid fat (that is, butter). Finally, since fat is lighter its expulsion is aided by the use of an eccentric nozzle syringe, especially if the nozzle is tilted up as is done to expel air bubbles. Even in the horizontal position the eccentric nozzle syringe seems to be better. If the syringe and pump are tilted up care must always be taken to fix them well to ensure stability and to avoid accidental fall. Additional suggestions include the use of shorter feeding and connecting tubes, complete emptying of the syringe at the end of each feed, and the early initiation of intermittent bolus feeding. It would also be beneficial if manufacturers of infusion pumps and syringes ensured a basic uniformity of design to allow easy fitting.
It is important to make sure that all the nutrients in human milk are actually delivered to the infant.

\footnotetext{
References

1 Spencer SA, Hull D. Fat content of expressed breast milk-a case for quality control. Br Med J 1981:282:99-10().

2 Lucas A. Gibbs JAH, Lyster RW, Baum JD. Creamatocritsimple clinical technique of estimating concentration and energy value of human milk. Br Med J 1978:i:1018-20.

${ }^{3}$ Hytten FE. Clinical and chemical studies in human lactation. Br Med J 1954:i: 175-82.

+ Hall B. Changing composition of milk and early development of appetite. Lancet 1975;i:779-81.
}

Correspondence to Dr I Narayanan, No 7 Type VI Quarters, MAMC Campus, New Delhi 110002, India.

Received 27 January 1984
Untreated, severe ornithine transcarbamylase deficiency causes fatal neonatal hyperammonaemia. Treatment prolongs survival but only two boys living more than 18 months have been reported-one aged 22 months with normal development and one 5 year old with severe psychomotor retardation. ${ }^{1} \mathrm{We}$ report a third.

\section{Case report}

A boy born in June 1981, the fourth child of unrelated French parents, was transferred to this hospital aged 3 days. His brothers had died as neonates - two from congenital malformations with no hyperammonaemia and one from ornithine transcarbamylase deficiency. His mother is asymptomatic but her serum ammonia and urine orotic acid concentrations rose abnormally on protein challenge. Jejunal biopsies in both parents showed normal ornithine transcarbamylase activity.

On hospital admission the boy was unresponsive with a serum ammonia value of $714 \mu \mathrm{mol} / \mathrm{l}$ (normal value less than $60 \mu \mathrm{mol} / \mathrm{l}$ ) and he had Escherichia coli septicaemia. Intravenous antibiotics and a dietary mixture given by gavage stopped deterioration, but on day 7 osmotic diarrhoea led to dehydration and coma and his serum ammonia value was $819 \mu \mathrm{mol} / \mathrm{l}$. He improved with exchange transfusion, diluted feeds, and sodium benzoate and was clinically normal on day 10 . After milk feeding was started on day 18 he thrived and his height and growth centiles were -2 SD and -1 SD respectively.

He has had three febrile illnesses and three immunisations without problem. At age 3 months he had a needle liver biopsy. At age 19 months he had a 